\title{
The Consequences of Incarceration for Mortality in the United States
}

\author{
Sebastian Daza \\ Center for Demography and Ecology \\ University of Wisconsin-Madison \\ sdaza@ssc.wisc.edu
}

Alberto Palloni

Center for Demography and Health of Aging

University of Wisconsin-Madison

palloni@ssc.wisc.edu

Jerrett Jones

Center for Demography and Ecology

University of Wisconsin-Madison

jbjones@ssc.wisc.edu

September 20, 2019

Keywords: Incarceration, Mortality, United States, United Kingdom, Health Inequality, PSID, NLSY, Decomposition

${ }^{*}$ The University of Wisconsin-Madison researchers are supported by core grants to the Center for Demography and Ecology, University of Wisconsin (R24 HD047873) and to the Center for Demography of Health and Aging, University of Wisconsin (P30 AG017266), and a small grant for research using PSID Data through the National Institute on Aging (P01AG029409). 


\begin{abstract}
Previous research suggests that incarceration has negative implications for individuals' well-being, health, and mortality. Most of these studies, however, do not follow former prisoners over an extended period of time and into older adult ages when the risk of health deterioration and mortality is the greatest. This paper contributes to this literature by employing for the first time the Panel Study of Income Dynamics (PSID) to estimate the long run association between individual incarceration and mortality over nearly 40 years, and supplementing those analyses with the National Longitudinal Survey of Youth 1979 (NLSY79). We then use these estimates to investigate the implications of the US incarceration regime and the post-1980 incarceration boom for the US health and mortality disadvantage relative to industrialized peer countries (the United Kingdom).
\end{abstract}




\section{Introduction}

The growth in the incarcerated population is a widely acknowledged fact of contemporary American life that has been increasingly studied by social scientists (National Research Council, 2014). Research shows that incarceration is negatively associated with a host of outcomes for individuals themselves as well as their kin and close relationships, including employment and wages (Pager, 2003; Western, 2002), union stability (Massoglia \& Warner, 2011; Turney, 2015), and children's health, behavior and development (Foster \& Hagan, 2014; Wildeman, 2009). Furthermore, an emerging line of research considers the consequences of incarceration for individual's health and well-being. Recent studies find that those with an incarceration history report higher chronic health problems (Schnittker \& John, 2007), lower self-reported health (Massoglia, 2008a), higher obesity (Houle \& Martin, 2011), more infectious diseases, stress-related illness (Massoglia, 2008b), and psychological disorders (Massoglia \& Pridemore, 2015).

Despite increasing interest in understanding the impact of incarceration on health, few studies investigate its long-term consequences for individuals' mortality risks, mostly due to data limitations (Massoglia \& Pridemore, 2015). This is an important shortcoming in the current body of research. First, the health and mortality impacts of incarceration on the US population are quite different if its health-related effects are experienced in the short instead of the long run. This is because short-term effects are likely to involve a much younger sub-population than long-term effects. Furthermore, from a public health stand perspective the distinction is crucial as the nature of preventative measures and associated health costs are entirely different in each case.

Previous research on the relationship between incarceration and health primarily relies on a handful of data-sets including the Fragile Families and Child Wellbeing Study, the National Longitudinal Survey of Youth 1979 and 1997 (NLSY), the National Longitudinal Study of Adolescent Health (Add Health) (Massoglia \& Pridemore, 2015), or administrative data (Evelyn J Patterson, 2010; Evelyn J. Patterson, 2013; Binswanger et al., 2007). While these studies make significant advances, they are limited in that they do not follow individuals over long swaths of time and thus cannot estimate effects that unfold during the older adult phase of an individual's life course when 
the risk of health deterioration and mortality is the greatest.

Importantly, extant individual level analyses of the association between incarceration and health rarely, if ever, examine the population level implications of their estimates. This is especially unfortunate for a number of reasons. To begin with it is impossible to assess accurately the ultimate health consequences of shifts in federal policies regulating incarceration. This is not trivial since it affects a particularly vulnerable subpopulation. Second, ignoring the population level consequences of ill-health and excess mortality brought about by incarceration rules out any study of the role it may play on contributing to at least well-known but underexplained phenomenon. One is the persistent US Black-White health and mortality disparities. The other is the perplexing US health and mortality disadvantage relative to peer countries. What is the role of the recent expansion of the criminal justice system in the expanding (contracting) Black-White disparities? How much of the recent increase in the adult health and mortality gap between the US and West European countries can be due to shifts federal incarceration policies? Although data limitations prevent us from addressing the first question, we are able to investigate the second one.

Thus, this paper makes two key contributions to this area of research. First, we estimate the long-term association between incarceration and adult mortality using two data sets: the Panel Study of Income Dynamics (PSID) (main analysis) and the National Longitudinal Survey of Youth 1979 (NLSY79) (sensitivity analysis). To our knowledge, no previous studies uses the PSID to explore the relationship of interest over such an extensive period (including the time interval before the incarceration boom). NLSY79, in turn, has been used previously (for instance, Massoglia, Pare, Schnittker, and Gagnon 2014), but only considering premature deaths. We expand those analyses using the new NLSY79 data available to explore longer periods after incarceration.

Our second contribution is to shed light on the macro-level impact of US mass incarceration on adult mortality. We use empirical estimates of excess mortality among formerly incarcerated adult populations to compute low-bounds for the magnitude of the contribution of US incarceration to the US adult mortality disadvantage relative to peer countries (the United Kingdom). Although tentative, these estimates highlight the significance of US incarceration policies and practices for 
adult US mortality levels, trends, and patterns, thus expanding previous research based on aggregate data (Christopher Wildeman, 2016). The analysis demonstrates that the investigation of excess mortality among those incarcerated has much larger implications than those associated with the population affected.

\section{Incarceration and Heath: Causal pathways}

A number of mechanisms can explain the association between incarceration and long-term adult health and mortality. Figure 1 summarizes those most notable pathways discussed in the literature. The pathways in the figure are represented by lines connecting personal and contextual factors both to mortality and incarceration.

First, the experience of imprisonment may increase the risk of contracting physical or mental illness. This, in interaction with post-imprisonment exposures, could increase accumulated adult mortality risks. Second, even in the absence of after-effects of exposures while imprisoned, released individuals may face disadvantageous residential, labor, and familial conditions that are detrimental to their physical and mental well-being. An important factor that may worsen conditions is the powerful social stigma of past incarceration. Third, for some individuals at least, prison offers safety features they cannot enjoy outside of it. Thus, routine access to medical care may reduce some health risks both during and after life in prison. More frequent contact with health facilities and medical personnel may increase knowledge and vigilance leading to reduced exposures long after individuals are released from prison.

These three mechanisms (exposure to risks while incarcerated, increase of disadvantage after release, and protection from external risks due to imprisonment) involve a direct causal impact of imprisonment on long term adult health status and mortality. The first mechanism is not mediated but could be modified by post-prison release environments. The second explanation is mediated by stigma and factors directly related to it that are the result of life in prison whereas the third mechanism depends on specific characteristics of the prison environment which individuals experience 
while incarcerated and outside prison.

Fourth, individual' traits that attenuate (enhance) the risk of imprisonment may also attenuate (enhance) the risk of adult ill-health thus producing an association between imprisonment experiences and long term mortality that is not due to a direct causal effect. Thus, for example, individual propensity to violence associated with antecedent mental illness could translate both in behaviors that lead to prison and to personal injury after release. Conversely, individuals who enter prison may be, on average, healthier than those of similar characteristics who do not and could experience lower ill-health and mortality risks after release by virtue of these antecedent traits.

Finally, there is strong empirical evidence suggesting that prisoners share characteristics (e.g., social disadvantage, family instability) that are related to both criminal activities and involvement in the criminal justice system's and individual health and mortality. In this case the observed association between imprisonment, on one hand, and ill-health and mortality on the other, would be spurious.

In this paper we are interested in assessing the total magnitude of effects (first, second and third pathways with solid lines in Figure 1) and seek to estimate these with rich longitudinal panel data. We acknowledge, however, that the relations portrayed in Figure 1 are complicated and in the absence of randomized controlled trials it is very difficult to rule out contamination of estimates attributable to selection or spuriousness. As a result, empirical estimates of the magnitude of the effect in this, as in other population-based studies, must be interpreted with caution $[1$

\subsection{Direct effects during incarceration}

Previous research suggests that prison populations have characteristics that increase exposure to various health risks and mortality during the prison term served. Prisoners are often held in overcrowded and unsanitary conditions that are conducive to the spread of communicable diseases. This may account for the fact that incarcerated populations experience higher rates of infectious

\footnotetext{
${ }^{1}$ In the remainder of the text we use the terms "effect" or "impact" of condition $X$ on mortality as shorthand to mean the estimated regression coefficient of condition $X$ on mortality. We do this to avoid terminological cluttering, not to equivocate. We invoke causal language only when we think it is legitimate to do so.
} 
diseases (National Research Council, 2014). According to the Centers for Disease Control and Prevention, 2011, prevalence of syphilis, gonorrhea, and chlamydia are higher among inmates in correctional facilities than in the general population. These are all conditions that, in the absence of timely screening and adherence to treatment, may impair the health of individuals years after they leave the prison.

Similarly, prison environments expose individuals to both chronic and acute stress and promote unhealthy behaviors, trigger mental health problems and physical injury. This could explain drug abuse, depression, chronic anxiety, poor self-rated health, and plummeting life satisfaction. Additionally, extreme exposures, such as solitary confinement, increase the risk of fatal self-harm (e.g., hanging and ingesting poison).

As is the case of communicable diseases, unhealthy behaviors and ill-mental health may influence individuals not only during their prison term but could have strong lagged effects spread over an individual's post prison adult life. The impact of communicable diseases, mental illness and unhealthy behaviors during life in prison and its post-release effects may become worse or better depending on the prison setting and, importantly, on whether or not it hosts routine access to prevention and treatment programs.

\subsection{Effects after incarceration}

Increases in health risk during incarceration may have a long reach and influence exposures, choices and behaviors after release. Individuals who experience incarceration spend on average far more time out of prison than in it: their exposure out of prison is nearly six times as long as their exposure as prison inmates (Christopher Wildeman \& Wang, 2017). Although short positive shocks (i.e., health care access, protective environment) might have long-term and cumulative consequences for health, former inmates face challenges that may outweigh transient benefits associated with imprisonment. They are often released without medications or follow-up appointments, and are less likely to have a primary care physician. They have no or only precarious housing, employment, family support, and experience discrimination when applying for jobs and housing. 
Consistent with these challenges, empirical evidence shows a deleterious impact of past incarceration experiences on health. Binswanger et al., 2007, for example, finds that after adjusting for age, sex, and ethnicity, the mortality rate for recently released inmates is 3.5 times higher than the rate for the general population during an interval of 2 to 5 years since release. Similarly, Rosen, Schoenbach, and Wohl, 2008, after adjusting North Carolina male administrative data for age, race (white/black) and educational attainment, conclude that ex-prisoners experienced more deaths than expected among other residents: standardized mortality ratios (SMR) for white and black former prisoners were 2.08 and 1.03, respectively (see also Spaulding et al.2011).

Evelyn J. Patterson, 2013, in turn, after following a cohort of parolees (1989-1993) for about 10 years, finds that an additional year in prison increases the odds of dying by $16 \%$ (about 2-year decline in adult life expectancy), and that the risk was highest early after release and decreases over time. Finally, Massoglia et al., 2014 report a significant association between incarceration and premature mortality for women, but not for men in the NLSY79.

\subsection{Selection Effects}

Some empirical research shows salubrious effects of life in prison and, in particular, reduced mortality and physical morbidity among inmates, especially black male prisoners, during incarceration. According to Mumola, 2007, mortality rates for state prisoners were about $20 \%$ lower than the resident population from 2001-2004. Evelyn J Patterson, 2010 further bolsters these findings using data from the BJS and the Census Bureau from 1985-1998 showing that mortality rates declines while in prison, especially for African-American males.

One explanation of this pattern is the healthy prisoner hypothesis which argues that individuals who engage in criminal behavior are, on average, in better health than the general population. This conjecture is based on the healthy worker hypothesis according to which productive and active individuals (those more likely to enter the workforce) have a lower risk of mortality and morbidity in comparison with those unemployed. Research by Baćak and Wildeman, 2015, however, shows that there is little support for the healthy prisoner hypothesis, and suggest that the association 
between incarceration and health is attributable to factors emerging during and after imprisonment.

Another explanation of lower mortality among those in prison is that imprisonment offers a protective environment and spending time in prison may decrease the risk of death by violence or accidents, reduce access to illicit drugs and alcohol, and improve health-care access. These mechanisms, however, may hold mostly for black male prisoners but less so for other groups. For instance, there might be heterogeneous effects due to both the variability in the quality of medical care across prisons and differences in imprisonment experiences. (Christopher Wildeman \& Wang, 2017). Finally, it is also possible that inmates with particularly poor health and close to death are systematically released (i.e., compassionate release), resulting in changes in composition of prisoners by health status. Figure 1 represents compassionate release by connecting frailty and release.

Although the discussion above refers to effects of imprisonment on health and mortality during imprisonment, it is possible that some of the factors on which these effects depend enhance (depress) health and mortality after release and are thus part of a different pathway.

\subsection{Long-term mortality effects of incarceration and its implications}

Due to data limitations, previous studies of incarceration and post-release mortality have focused mainly on short-term effects of incarceration on mortality (Massoglia \& Pridemore, 2015). The first goal and contribution of this paper is to use two rich panel datasets to estimate the total association between individual incarceration experiences and long-term adult mortality (e.g., the association produced by pathways with solid lines in Figure 1) and manifested after incarceration experiences. Our conjecture is that because of exposure during life in prison and/or due to negative post-imprisonment familial, residential, economic, and emotional challenges with strong influence of health and well-being, mortality rates will be consistently higher among former inmates when compared to rates for individuals with no imprisonment experiences despite any protective effect incarceration might have. We are not arguing, though, that the effect of incarceration is higher later after release from prison, but that both immediate effects (closer to the release) and long-term 
consequences of imprisonment (later after the release) might have significant detrimental impacts in population health, and that a proper way to estimate cumulative effects of incarceration on mortality requires examining long-term associations and extensive longitudinal data $2^{2}$

The second goal and contribution of the paper is to generate preliminary estimates of the influence of excess mortality among formerly incarcerated adults on the US mortality disadvantage relative to peer countries in Western Europe (the United Kingdom). We conjecture that, owing to the relative size of the population of interest in the US and the expected excess mortality, postprison mortality patterns will have non-trivial impacts of roughly the same order of magnitude as that of other candidate mechanisms.

\section{Data and Measures}

Our main analysis employs the Panel Study of Income Dynamics (PSID). The PSID is one of the most widely used population surveys and one of its strengths is the longevity of the sample design. The PSID follows a nationally representative sample of 15,000 individuals living in 5,000 families in the United States, beginning in 1968 with annual follow-up interviews through 1997 and biannual thereafter. Moreover, we use the National Longitudinal Survey of Youth 1979 (NLSY79) to undertake sensitivity analysis and verify whether or results from examination of NLSY are similar to those obtained from PSID. For more details see the section Sensitivity Analysis below.

\subsection{Mortality}

Our dependent variable is mortality (year of death) and is retrieved from information from the National Death Index (NDI) and PSID non-response records. Between 1968 and 2013, 6863 respondents died during the observation period ( $9 \%$ of respondents with at least one valid record).

\footnotetext{
${ }^{2}$ We explored whether or not the association between incarceration and mortality changes after the release of inmates (not shown). Our results are consistent with the literature and previous research (i.e., the risk of mortality is highest early after release and decreases over time). However, because our sample is too small to sustain robust inferences, we did not estimate the magnitude of the differences between long and short term effects. This issue should be explored in future research.
} 
Records for individuals whose deaths took place between 1979 and 2013 were matched to the NDI to obtain precise dates at death (see the PSID Death File documentation for details). For deaths that took place before 1979, we use the PSID year of death (Death File 2015). When the PSID provides a range for the year of death, we impute an exact date as the middle point of the interval (e.g., 1980-1986 = 1983). In total, $76 \%$ of deaths in our analysis were matched to the NDI ${ }^{3}$

\subsection{Incarceration indicators}

Our key independent variable is incarceration and is measured using two indicators from PSID sources (for more details see the Online Appendix). First, we use non-response information on whether a member of a household was incarcerated at the time of the interview. According to this variable, 627 individuals were in prison at any wave. The major disadvantage of this indicator is that it misses short spells of imprisonment and, therefore, could generate downward biases in estimates of the association between incarceration and mortality. Figure 2 shows weighted and unweighted proportions of respondents in prison by year using the non-response incarceration variable. As seen in the figure, the trend of observed imprisonment is consistent with significant increases in the number of people behind bars since 1972 in the United States. The magnitude of the incarceration rate from PSID, however, is somewhat lower than figures reported by the Bureau of Justice Statistics (National Research Council, 2014). This suggests that, as conjectured before, the PSID non-response incarceration records under report imprisonment. ${ }^{4}$

Our second indicator of incarceration uses a set of questions about involvement with the criminal justice system. One of them, asked respondents in 1995 whether they had been in jail or prison. According to this variable, 1995 incarceration, 838 individuals were in prison before 1996.

Finally, we use a combination of these two indicators. Since mortality and imprisonment are rare events, combining both measures maximizes the statistical power of our estimates. To do so we create a time-varying incarceration variable for year $t$ that attains a value 1 if there was

\footnotetext{
${ }^{3}$ The distribution of the age of death is shown in Figure $\mathrm{S} 1$ of the Online Appendix

${ }^{4}$ The distribution of the age of first imprisonment is shown in Figure 1 1 of the Online Appendix.
} 
information on respondent's imprisonment by year $t$, and 0 otherwise. For 1995 incarceration, we use information about the year of the last release to define an imprisonment event (every period after release was coded as 1). We then combine both variables and, to avoid survival selection bias, we exclude those who died before 1996. According to the combined indicator, 1285 persons (1.7\% of respondents) were ever in jail/prison at any time during the observation period. Although both incarceration measures may be affected by measurement error, most errors will be due to under-reporting caused by either short spells of incarceration or desirability bias.

\subsection{Control variables}

To minimize contamination by selection and confounding, all models adjust for individual and household characteristics. A major concern, however, is to avoid adjusting for variables measured after the event of interest (i.e., incarceration). We adjust for covariates such as age, gender, race, education attainment, household income, and self-reported health. We prioritize relevant and wellmeasured variables that cover most of the observation period per respondent. Age is included as a fixed covariate and its value is set at the beginning of the observation (time $=0$ ). Respondents' race and ethnicity was available only for the head of households and their spouses. For the remaining population we imputed race using the head of household's race. Educational attainment, originally measured in years of education, was recoded into four categories (less than high school, high school, some college, and college). Household income was adjusted for inflation (2013) and then $\log$ transformed. Finally, self-rated health, a time-varying covariate measured since 1986, was recorded using a 5-point scale (excellent, very good, good, fair, and poor) and applied to heads of households and their spouses. For the remaining household members we only know if whether they were in poor health or not (binary variable). To establish comparability, we recode the variable and the last two categories of the 5-point scale (fair and poor) are used to create a poor health single binary variable. 


\subsection{Analytic Dataset}

We arrange the PSID dataset in a person-year format, so that records represent observations from time 0 (when respondents started at the PSID) to time $t$, the last time a respondent was interviewed. Because since 1997 PSID interviews were conducted bi-annually, we expand those intervals to create an annual dataset. We define an observation as valid when respondents were present in a Family Unit (FU), in an institution, or died during that year. That is, we include both sample and non-sample respondents according to PSID's terms. Sample respondents are those who belong to the original 1968 family for the core PSID sample or the original 1997 family for the Immigrant sample. Non-sample members are those respondents added later who were not related by blood or adoption to any PSID sample member.

The dataset for analysis (excluding deaths before 1995) includes 48,340 respondents (48.7\% males). The average age at the start of PSID was 28 years (median $=23$ ), while the average exposure (or observation window) was 13 years (median $=7$ ), with a minimum of 1 and maximum of 46 years. $56 \%$ of the sample is white, $34 \%$ African-American. A total of 2719 deaths were registered (after removing records with missing data) and 73 respondents were in prison and died during the observation period. Among these the average number of years between the last spell of incarceration recorded and the year of death was 14 (median $=12)$. Those deaths occurred on average at age 47 (median $=49$ ), and $22 \%$ occurred during the first 5 years after release at the average age of 38. Because our indicator of release from prison is based on non-response records in the PSID, it is subject to error and should not be taken as a precise measure of date of release.

To ensure an internally consistent analytic dataset devoid of coding errors, we employ a simple multistate simulation model with arbitrary parameters and verify that simulated outcomes obtained from the analytic dataset and the arbitrary parameters reproduce the input parameters (see the Online Appendix). The analytic data set described above has shortcomings. First, the number of respondents who were both in prison and died is small, preventing us from identifying precisely differences by gender, race, cause of death, age, and cohort. As a consequence throughout our analyses we focus on the gross association between imprisonment experiences and mortality and 
do not engage in the exercise of establishing fine tuned contrasts between gender, races or ages. Second, given the sample size, our estimates might be upwardly biased due to Type M error, namely, conditional on statistical significance, the noisier the estimate is, the higher the chance of overestimating the magnitude of the effect (Gelman \& Carlin, 2014). One way to address this issue is to use additional data and prior information to evaluate the plausibility of our estimates. We briefly discuss this point in the final section of the paper and assess the magnitude of our estimates relative to those found in previous literature.

\section{Models and estimation strategy}

We use both parametric (Gompertz) and semi-parametric (Cox) survival models to estimate the association between incarceration and mortality. Parametric models allow us to validate the data setup and to verify consistency of the adult mortality pattern we find in the data (constant and slope of the Gompertz model) with US national data. Semi-parametric models, were used to test sensitivity of estimates to alternative specifications. They also enable us to produce estimates of the association between incarceration and mortality using different sampling weights, handling alternative missing data strategies, modeling unobserved heterogeneity specifications, and employing marginal structural models (MSM). The semi-parametric models yield bounds and ranges rather than point estimates and thus lead to more conservative inferences (see the Online Appendix for more details).

We first estimate a baseline model that adjusts only for demographic characteristics such as age, gender, and race/ethnicity. We then add two time-dependent covariates: the centered log of household income and education attainment by time $t$. Finally, we add poor health to adjust for any potential confounding between health, incarceration and mortality. Given the time-dependent nature of our key independent variable (incarceration) and confounders (e.g., income, education, and poor health), we estimate marginal structural models (MSM) by using stabilized inverse probability weights (van der Wal \& Geskus, 2011). Once these estimates are in place we proceed with 
diagnostic tests of the parametric model and estimation of non-parametric models (see the Online Appendix for more details).

\section{Results}

We begin by estimating Gompertz models using the PSID data and comparing the slope of those models with the estimates obtained using the US vital statistics and census population. This exercise provides a good benchmark to judge the accuracy of the data and suitability of the model. Table 1 displays Gompertz models using different controls and no sampling weights. The Gompertz model includes a parameterized baseline hazard that depends on two parameters, a constant, $\alpha$ and a slope (or shape) $\gamma$. The parameter $\gamma$ is a measure of the rate of increase of mortality rates at older age whereas the constant is a measure of levels of mortality at approximately age 18 when all covariates are set to 0 . Covariates influence the magnitude of the constant only and we constrain the slope to be invariant across subpopulations 5

The value of $\gamma$ for the male 2010 US life table is .095 (Arias, Heron, \& Xu, 2017). Our baseline models in Table 1 lead to an estimate of $\gamma$ in the neighborhood of 0.13 , within the expected human range but somewhat higher than the one in the US life table. Comparisons of the values of the (exponentiated) estimate of the Gompertz constant with the US mortality rate at around age 20 are less meaningful since our estimates are based on very few events in the vicinity of ages 18-25. Moreover, because it is a measure of mortality levels in the left out groups (all covariates set to zero) it is not an average measure of mortality and, therefore, is not directly comparable with the US life table. In contrast, the estimate of the slope reflects experiences during a stage of the life cycle when mortality increases rapidly, and the number of events on which the estimate is based is larger than the points of support available for the estimate of Gompertz's constant.

The effects of imprisonment in Table 1 ranges between 0.74 and 0.97 in the models with de-

\footnotetext{
${ }^{5}$ The variability of the slope in humans is restricted to a somewhat narrow range (.05-.14) (Kirkwood, 2015). We expect our estimates to be within that range. We opt for not letting the Gompertz slope be a function of covariates (some of them identical to those that modify the constant) because this leads to intractable identification problems, even in very large samples.
} 
mographic adjustments, that is, hazard rates for former prisoners are between 2.10 and 2.64 times higher than hazard rates for those who have not been in prison by time $t$ (after adjusting for other covariates), with standard errors considerably smaller than the size of coefficients. These differences in mortality rates translate into differences in life expectancy at age 45 of (approximately) 4 to 5 years or roughly 14 percent of the value of US male life expectancy at age 50.

\subsection{Sensitivity Analysis}

We assess the sensitivity of estimates obtained by varying model specification, using different strategies for panel attrition and missingness, and using a different dataset.

\subsubsection{Model Specification and Panel Attrition}

To help assessment of the effects of panel attrition we estimate additional Cox models and Marginal Structural Models with various specifications. First, Tables 2 and 3 shows results of Cox models using both unweighted and weighted samples and four model specifications. We define two set of models: (1) adjusting only for sociodemographic covariates only, and (2) adjusting for sociodemographic covariates and health. Within these two sets, we estimate models with and without marginal structural effects (MSM). Coefficients in Tables 2 and 3 are about the same order of magnitude than what we observe in Table 1 (hazard ratios from 1.88 to 2.69), and they behave as expected. Income and education coefficients are consistently negative, and poor health (measured since 1986) is, not surprisingly, highly associated with mortality. Figure 3 shows cumulative mortality by incarceration status (probability that an individual died by time $x$ ) at age 18 and 30 using the model $M 1$ in Table 2. An individual who started out as a PSID member at age 18 (time or year $=0$ ) and is incarcerated, will experience an probability of dying after 40 years of about 0.37 , while someone who was not incarcerated will experience an accumulated probability of dying of about 0.20 .

Second, the marginal structural models use two scaled weights - one correcting for attrition (drop out) and the other for exposure (incarceration). The estimates from the MSM yield slightly 
smaller hazard ratios associated with imprisonment (from 1.88 to 2.01). Models with sampling weights (Table 3) leads to higher hazard ratios: former prisoners experience mortality rates between 2.41 and 2.69 times higher than those for the population that has not been in prison by time $t$. Standard errors from weighted models are, as expected, higher, and regression estimates are more uncertain. While unweighted models have coefficients about 4.3 times larger than standard errors, weighted models show a slightly lower ratio (3.5).

\subsubsection{Missingness}

Multiple imputation do not change imprisonment estimates. Point estimates of hazard ratios in Tables $\mathrm{S} 1$ and $\mathrm{S} 2$ in the Online Appendix range from 1.86 to 2.36. Standard errors, though, are much higher, specially when using sampling weights: The average ratio between coefficients and standard errors is 3.49 without weights and 2.75 with weights. Thus, the existence of missing data augments the uncertainty of our estimates even though it does not appear to alter their mean values.

\subsubsection{NLSY 79}

We estimate parameters using complete NLSY79 cohort through 2014 (584 deaths) thus including a 34 year follow-up period. We employ marginal structural models (MSM) to adjust for timevarying confounders while avoiding over-controlling for them (Hernán \& Robins, 2006). We follow the same analytic approach used when analyzing the PSID data but are able to include a much richer set of covariates.

Simple hazard imprisonment coefficients are close to zero (or negative) and with large uncertainty bounds (see Tables $\mathrm{S} 3$ and $\mathrm{S} 4$ in the Online Appendix). The covariates are properly signed: males have a higher risk of mortality; income, education, working status, and married are associated with lower risks; and, finally, poor (self-reported) health is a strong predictor of mortality. The marginal structural models, on the other hand, show positive and more accurate coefficients for incarceration (hazard ratios ranging from 1.73 to 1.77 ). Thus, results from the NLSY and PSID are consistent despite the fact that these data sets include completely different cohorts and cover 
periods of time that are only partially overlapping. This strengthens our confidence on estimates from the PSID data.

\section{Implications of excess mortality due to incarceration}

It is a relatively simple exercise to translate the estimates of excess mortality disclosed in the previous section into a more transparent metric such as the life expectancy at age 40. As mentioned earlier, we estimate that incarceration's adult mortality excess translates into a loss of between 4 and 5 years of life expectancy at age 40. Although this is an improvement over the more opaque metric of relative risks used before, it still does not render the full significance of the estimates. To do so one needs to investigate further their broader implications. That some of these implications are quite significant is demonstrated by results of previous research whose objective is to assess the impact of individuals' incarceration on their own well-being, health and mortality and that of related individuals (close kin, spouses and children, neighbors). A small body of that research is dedicated to evaluate the impact of aggregate levels of incarceration on US national levels of health and mortality (Christopher Wildeman, 2016). In this section we contribute to this literature by examining the implications of US incarceration experiences for recent adult US mortality. In particular, we explore the possibility that past US incarceration policies and practices may have contributed significantly to the persistent adult mortality disadvantage of the US relative to peer countries. To do so we transform the estimates obtained from our models into (expected) excess adult mortality in the US population attributable to past incarceration experiences. These transformations amount to computing counterfactual differences, e.g., differences between current mortality levels in the US total male population (or some other of its subpopulations) and what we would observe if incarceration had no mortality effects or if the rates of incarceration were zero. 


\subsection{Background: the NRC reports}

A number of recent reports show that the US does not rank well among peer countries in terms of adult health and mortality. In particular, health status indicators and mortality rates among young adult males and females (20-44 years old) and older adults (45-69) (but not the very old) rank close to the bottom of the distributions (National Research Council, 2014). Could it be that part of the observed disparities are accounted for by differential incarceration experiences and excess mortality risks? To what extent is the US health and mortality disadvantage among young and older adults accounted for disparities in the composition of populations by incarceration experiences? In light of both differences in rates of incarceration in the US vis-a-vis other countries (Christopher Wildeman, 2016) and of qualitative and quantitative evidence showing that imprisonment experiences increase health risks and mortality, these are not far-fetched questions. Furthermore, over the last forty years the US penal system has experienced a large expansion (National Research Council, 2014) and this, jointly with excess health and mortality risks of the population that experiences imprisonment, is consistent with a gradual trend of increased US deterioration relative to peer countries. We ask the following question: how much of the gap in mortality between the US and peer countries can be attributable to differential imprisonment experiences?

\subsection{Estimation}

To approximately assess the contribution of the association between incarceration and mortality to the poor US health and mortality ranking, we decompose the difference of mortality between the US and the UK and estimate what fraction of that difference could be attributed to differences in rates of incarceration in both countries. This provides a first approximation to the question of how much differential incarceration regimes contribute to the US adult mortality disadvantage relative to peer countries. We implement a very simple procedure and compute the fraction of the difference of mortality rates in two age ranges between the US and the UK. The procedure rests on two simplifications. First, a more systematic tests of the conjecture should be based on comparisons with multiple populations. However, the requisite data for the exercise are available 
only for the UK. Further, together with Canada, the UK is one of the two peer countries that most resembles the US on a number of dimensions and because its population most resemble the US population in terms of demographic profiles, ethnic diversity, culture, and language 6

Second, we employ only two age groups: 20-45 and 20-70. The choice of the wider older age group is justified on the grounds that the mortality effects of imprisonment we estimate include the population older than 45 and it is this older population that could experience the brunt of excess mortality risks. The choice of the younger age group serves the purpose of constraining the computations to a sub-population more likely to be vulnerable in the future as their imprisonment experiences are surely more recent and the consequences have not yet fully unfolded. These estimates are preliminary and should be interpreted with caution.

The mortality gap between the US and a peer country is given by:

$$
D_{(x)}=M U_{(x)}-m u_{(x)}
$$

where $M U_{(x)}$ is the mortality rate at age $x$ in the US, and $m u_{(x)}$ the mortality rate in the peer country. The rates are defined as:

$$
\begin{gathered}
M U_{(x)}=M U o_{(x)} \times\left(P_{(x)} \times(E-1)+1\right)=M U o_{(x)} \times H_{(x)} \\
m u_{(x)}=\operatorname{muo}_{(x)} \times\left(p_{(x)} \times(E-1)+1\right)=m u o_{(x)} \times h_{(x)}
\end{gathered}
$$

where $\mathrm{MUo}_{(x)}$ and $m u o_{(x)}$ is the mortality rate at age $x$ among those who have not been in prison in the US and peer country, respectively; $P_{(x)}$ and $p_{(x)}$ is the fraction of the population not currently in prison but that has been in prison in the past in the US and the peer country respectively and, finally, $E$ is the relative risk of mortality of those who had been in prison. We assume throughout

\footnotetext{
${ }^{6}$ There are many and very strong reasons to use UK and not France or Russia as a benchmark. First, in key studies of the US adult health and mortality disadvantage, the UK is used as the preferred benchmark (Banks, Marmot, Oldfield, \& Smith, 2006) because of similarity of culture and language and contrasts of medical health care system. Ideally, we would have liked to produce a full comparison with all countries included in the NRC report, but that is left for future work. In terms of the criminal justice system, comparisons between the US and UK are not rare, either. Garland, 2002, for instance, claims that there are strong similarities in the recent criminal policies and practices and this alone makes the comparison interesting.
} 
that the mortality excess of people who have been imprisoned is the same in the US and peer country. The expression for the gap can be rewritten as follows:

$$
D_{(x)}=A_{(x)}+B_{(x)}
$$

where

$$
\begin{aligned}
& A_{(x)}=\frac{H_{(x)}+h_{(x)}}{2} \times\left(M U o_{(x)}-m u o_{(x)}\right) \\
& B_{(x)}=\frac{M U o_{(x)}+m u o_{(x)}}{2} \times\left(H_{(x)}-h_{(x)}\right)
\end{aligned}
$$

$A_{(x)}$ is the contribution of differences in mortality in the population that have not experienced prison. The second term, $B(x)$, is the contribution to the total difference of the population who have been in prison. The fraction of the difference attributable to imprisonment is $\frac{B_{(x)}}{D_{x}}$ and the one due to other factors is $\frac{A_{(x)}}{D_{x}}$. These quantities were computed assuming that the incarceration rate $J_{(x)}$ and $j_{(x)}$ are invariant with age, $P_{(x)}=r \times J_{(x)}$ and $p_{(x)}=r \times j_{(x)}$.

Table 4 displays estimates for both age groups using alternative estimates of the effects of prison on mortality from Cox models. We use incarceration rates (per 100,000) for the US and UK 2011-2012 (National Research Council, 2014, p. 36), and mortality rates (per 1,000) for the different age groups in 2011 (Wilmoth \& Shkolnikov, 2008). Since we lack information for the UK we assumed that $p_{(x)}=r \times j_{(x)}$. Estimates for $P_{(x)}$ in the US are around $2 \%(2.05 \%$ according to Bonczar 2003, and 2.09\% to Shannon et al. 2017, and 1.86\% to Uggen, Manza, and Thompson 2006). Throughout we use the highest estimates. According to Table 4 , the contribution of differential composition by imprisonment to the mortality gap in the age group 20-70, $\frac{B_{(x)}}{D_{x}}$, ranges between $4 \%$ to $10 \%$ depending on which estimate of mortality effects we choose. In the narrower age groups, the results are more muted and the range for the proportionate contribution of imprisonment is between $3 \%$ and $6 \%$.

Two caveats are in order. First, the National Research Council Reports, where comparisons between the US and peer countries mortality are discussed, use a more fine-tuned aggregation of 
mortality rates by age than we do here. Ideally, our counterfactuals should be computed at the same level of aggregation as in the report. Unfortunately this is not possible in our case because the sparsity of events across the life course in PSID only enables us to estimate a single level of mortality with a fixed age pattern. This weakness is, however, inconsequential because the US age pattern of excess mortality is quite regular, at least between ages 20 and 69. It follows that the use of an even more simplified approach, with a single age group, instead of two as we do here, would have produced robust estimates.

Second, in an attempt to include a broader range of estimates of excess mortality among formerly incarcerated individuals, we gathered information from several sources and build a set of estimates from which we sample to compute counterfactuals. However, the range of these estimates turned out to be a subset of the range we used above and, therefore, could not possibly lead to different inferences, 7

Caveats aside, we hasten to emphasize that the main take-away message from this exercise should not be about precise magnitudes of target parameters but rather about order of magnitudes. The counterfactual estimates derived before rest on a number of somewhat fragile assumptions that although plausible must be ascertained with more accuracy than we are able to do here. Although they do not translate into massive contributions to the US-peer-country (UK) disadvantage, the estimates of effects we compute are non-trivial and of roughly the same order of magnitude as contributions attributable to other factors routinely considered relevant for adult mortality disparities, such as race and education (Olshansky et al., 2012; Centers for Disease Control and Prevention, 2017). Finally, note that these estimates rely on the highly conservative assumption that excess mortality risks due to past imprisonment is the same in the UK and the US. This could misrepresent the possibly more benign social and economic environments for post-prison life of UK's young adults and produce underestimates of the contribution of US incarcerations to its own mortality disadvantage.

\footnotetext{
${ }^{7} \mathrm{Had}$ the range of values been broader, we would have proceeded differently via Bayesian computations and imposing a prior distribution on estimates. This exercise is left for future research.
} 


\section{Conclusion and Discussion}

This paper uses the Panel Study of Income Dynamics (PSID) to estimate the long-term association between imprisonment and mortality in the US over a period of nearly 40 years. Our estimates point to a moderate association between incarceration and mortality, with relative risks ranging between 1.7 to 2.7 . These mortality excesses translate into losses of life expectancy at age 45 of about 4-5 years or 13 percent of current US life expectancy at age 45. Moreover, the sensitivity analysis employing the National Longitudinal Survey of Youth 1979 (NLSY79) shows associations in the same direction and of the same order of magnitude than those in PSID.

Only a handful of studies have examined incarceration and mortality with a long-term followup. Our estimates using the PSID and NLSY79, however, are in line with research showing a significant association between imprisonment and mortality. The magnitude of effects reported in previous studies ranges ratios between 1.32 and 2.56 (Massoglia \& Pridemore, 2015), a range values consistent with our estimates. This suggests our coefficients are not exaggerating the association between incarceration and mortality due to small sample size and Type $M$ error, but it might also mean that they suffer from the same biases as those in other studies. Further research will be need to clarify this sample size limitation.

Although we estimate the association between imprisonment and mortality in the US over a period of nearly 40 years, we are not able to identify the precise magnitude of differences between early and later effects due to sample size limitations. It is likely that most of them operate both in the short-term - inducing effects that are visible immediately after prison release (Evelyn J. Patterson, 2013) - and also in the long-term, unfolding over long stretches of time and spread over wide segment of an individual's adult life. Their identification is possible only through extended longitudinal studies with larger samples than those available to us.

In an attempt to uncover the substantive significance of our estimates, we investigated their implications for an important problem in social demography, namely, the US mortality disadvantage relative to peer countries. Thus, we estimate that the fraction of the mortality gap between the US and a single peer country (UK) that can be attributed to differential imprisonment experiences 
ranges from $3 \%$ to $10 \%$. These contributions are not large and cannot reflect massive influences but they are not trivial either and are of comparable order of magnitude than those attributed to better known factors such as education, health care, and race (Olshansky et al., 2012; Centers for Disease Control and Prevention, 2017).

Our analyses and model specifications are limited by the PSID and NLSY79 design, including timing and frequency of some key questions, attrition, and missing data. We made an effort to provide a range of estimates using different strategies and model specifications to explicitly disclose levels of uncertainty and of model dependency. Our models might also be seriously affected by selection: the paths linking personal and contextual characteristics to both incarceration and mortality in Figure 1. As a consequence, the counterfactual computations associated with the fraction of mortality gaps between the US and peer countries attributable to incarceration, are tentative and preliminary. Despite these limitations, our estimates of the contribution of incarceration to adult mortality gaps is useful because it provides a sense of the magnitude of the potential macro-level consequences of mass incarceration in the US. This can be readily extended to the study of other problems involving mortality gaps between sub-populations (e.g., Black-White mortality disparities).

Our paper represents a first step in a more comprehensive assessment of repercussions of the recent US expansion of the criminal justice system. Future research in this area should focus on two fronts. First, to obtain more precise and nuanced estimates of excess adult health and mortality due to incarceration experiences, including assessments by gender, race, and detailed age groups. Second, to investigate the implications of such estimates for some of the most startling features of modern US mortality patterns, such as recent time trends of disparities between adult White and African American male mortality. 


\section{References}

Arias, E., Heron, M., \& Xu, J. (2017). United states life tables, 2013. National Vital Statistics Report, 66(3), 1-64.

Baćak, V. \& Wildeman, C. [Christopher]. (2015). An empirical assessment of the "healthy prisoner hypothesis”. Social Science \& Medicine, 138, 187-191. doi:10.1016/j.socscimed.2015.05. 039

Banks, J., Marmot, M., Oldfield, Z., \& Smith, J. P. (2006). Disease and disadvantage in the United States and in England. JAMA, 295(17), 2037-2045. doi:10.1001/jama.295.17.2037

Binswanger, I. A., Stern, M. F., Deyo, R. A., Heagerty, P. J., Cheadle, A., Elmore, J. G., \& Koepsell, T. D. (2007). Release from prison - a high risk of death for former inmates. New England Journal of Medicine, 356(2), 157-165. doi:10.1056/NEJMsa064115

Bonczar, T. P. (2003). Prevalence of imprisonment in the us population, 1974-2001. U.S. Department of Justice, Office of Justice Programs. Retrieved from http://www.cbsnews.com/htdocs/ pdf/prisontime.pdf

Centers for Disease Control and Prevention. (2011). STDs in persons entering corrections facilities. Department of Health and Human Services.

Centers for Disease Control and Prevention. (2017). Health, United States, 2017: With special features on racial and ethnic health disparities. Department of Health and Human Services.

Foster, H. \& Hagan, J. (2014). Supportive ties in the lives of incarcerated women: Gender, race/ethnicity, and children's human rights. J. Gender Race \& Just. 17, 257. Retrieved from http://heinonline. org.ezproxy.library.wisc.edu/hol-cgi-bin/get\%5C_pdf.cgi?handle=hein.journals/jgrj17\% 5 C\&section $=16$

Garland, D. (2002). The Culture of Control: Crime and Social Order in Contemporary Society (1 edition). Chicago: University Of Chicago Press.

Gelman, A. \& Carlin, J. (2014). Beyond power calculations assessing type s (sign) and type m (magnitude) errors. Perspectives on Psychological Science, 9(6), 641-651. Retrieved from http://pps.sagepub.com/content/9/6/641.short 
Hernán, M. A. \& Robins, J. M. (2006). Estimating causal effects from epidemiological data. Journal of Epidemiology and Community Health (1979-), 60(7), 578-586.

Houle, J. N. \& Martin, M. A. (2011). Does intergenerational mobility shape psychological distress? sorokin revisited. Research in Social Stratification and Mobility, 29(2), 193-203. doi:10. 1016/j.rssm.2010.11.001

Kirkwood, T. B. L. (2015). Deciphering death: A commentary on gompertz (1825) 'on the nature of the function expressive of the law of human mortality, and on a new mode of determining the value of life contingencies'. Philosophical Transactions of the Royal Society B: Biological Sciences, 370(1666). doi:10.1098/rstb.2014.0379

Massoglia, M. (2008a). Incarceration as exposure: The prison, infectious disease, and other stressrelated illnesses. Journal of Health and Social Behavior, 49(1), 56-71. doi:10.1177/002214650804900105

Massoglia, M. (2008b). Incarceration, health, and racial disparities in health. Law \& Society Review, 42(2), 275-306. doi:10.1111/j.1540-5893.2008.00342.x

Massoglia, M., Pare, P.-P., Schnittker, J., \& Gagnon, A. (2014). The relationship between incarceration and premature adult mortality: Gender specific evidence. Social Science Research, 46, $142-154$.

Massoglia, M. \& Pridemore, W. A. (2015). Incarceration and health. Annual Review of Sociology, 41(1), 291-310. doi:10.1146/annurev-soc-073014-112326

Massoglia, M. \& Warner, C. (2011). The consequences of incarceration. Criminology \& Public Policy, 10(3), 851-863. doi:10.1111/j.1745-9133.2011.00754.x

Mumola, C. J. (2007). Medical causes of death in state prisons, 2001-2004. US Department of Justice, Office of Justice Programs, Bureau of Justice Statistics. Retrieved from https:// www.ncjrs.gov/App/AbstractDB/AbstractDBDetails.aspx?id=237953

National Research Council. (2014). The growth of incarceration in the united states: Exploring causes and consequences (J. Travis, B. Western, \& S. Redburn, Eds.). Washington, DC: The National Academies Press. Retrieved from https://www.nap.edu/catalog/18613/the-growthof-incarceration-in-the-united-states-exploring-causes 
Olshansky, S. J., Antonucci, T., Berkman, L., Binstock, R. H., Boersch-Supan, A., Cacioppo, J. T., ... Goldman, D. P., et al. (2012). Differences in life expectancy due to race and educational differences are widening, and many may not catch up. Health Affairs, 31(8), 1803-1813.

Pager, D. (2003). The mark of a criminal record. American Journal of Sociology, 108(5), 937-975.

Patterson, E. J. [Evelyn J]. (2010). Incarcerating death: Mortality in u.s. state correctional facilities, 1985-1998. Demography, 47(3), 587-607. Retrieved from http://www.pubmedcentral.nih. gov/articlerender.fcgi?artid=3000056\%5C\&tool=pmcentrez $\% 5 C \&$ rendertype=abstract

Patterson, E. J. [Evelyn J.]. (2013). The Dose-response of Time Served in Prison on Mortality: New York State, 1989-2003. American Journal of Public Health, 103(3), 523-528.

Rosen, D. L., Schoenbach, V. J., \& Wohl, D. A. (2008). All-cause and cause-specific mortality among men released from state prison, 1980-2005. American Journal of Public Health, 98(12), 2278-2284. doi:10.2105/AJPH.2007.121855

Schnittker, J. \& John, A. (2007). Enduring stigma: The long-term effects of incarceration on health. Journal of Health and Social Behavior, 48(2), 115-130. doi:10.1177/002214650704800202

Shannon, S. K. S., Uggen, C., Schnittker, J., Thompson, M., Wakefield, S., \& Massoglia, M. (2017). The growth, scope, and spatial distribution of people with felony records in the united states, 1948 to 2010. Working Paper.

Spaulding, A. C., Seals, R. M., McCallum, V. A., Perez, S. D., Brzozowski, A. K., \& Steenland, N. K. (2011). Prisoner survival inside and outside of the institution: Implications for health-care planning. American Journal of Epidemiology, 173(5), 479-487. doi:10.1093/aje/ kwq422

Turney, K. (2015). Hopelessly devoted? relationship quality during and after incarceration. Journal of Marriage and Family, 77(2), 480-495. Retrieved from http://onlinelibrary.wiley.com. ezproxy.library.wisc.edu/doi/10.1111/jomf.12174/full

Uggen, C., Manza, J., \& Thompson, M. (2006). Citizenship, democracy, and the civic reintegration of criminal offenders. The Annals of the American Academy of Political and Social Science, $605(1), 281-310$. 
van der Wal, W. M. \& Geskus, R. B. (2011). Ipw: An R package for inverse probability weighting. Journal of Statistical Software, 43(13), 1-23.

Western, B. (2002). The impact of incarceration on wage mobility and inequality. American Sociological Review, 67(4), 526-546. doi:10.2307/3088944

Wildeman, C. (2009). Parental imprisonment, the prison boom, and the concentration of childhood disadvantage. Demography, 46(2), 265-280.

Wildeman, C. [Christopher]. (2016). Incarceration and population health in wealthy democracies. Criminology, 54(2), 360-382.

Wildeman, C. [Christopher] \& Wang, E. A. (2017). Mass incarceration, public health, and widening inequality in the usa. The Lancet, 389(10077), 1464-1474. doi:10.1016/S0140-6736(17) 30259-3

Wilmoth, J. R. \& Shkolnikov, V. (2008). Human mortality database. University of California, Berkeley (US), and Max Planck Institute for Demographic Research (Germany). 


\section{Tables}

Table 1: Gompertz Models on the effect of Imprisonment on Mortality, Unweighted, PSID 1968-2013

\begin{tabular}{|c|c|c|c|}
\hline & Model 1 & Model 2 & Model 3 \\
\hline Prison & $\begin{array}{c}1.10 \\
(0.12)\end{array}$ & $\begin{array}{c}0.97 \\
(0.12)\end{array}$ & $\begin{array}{c}0.74 \\
(0.12)\end{array}$ \\
\hline Age & $\begin{array}{c}0.08 \\
(0.00)\end{array}$ & $\begin{array}{c}0.08 \\
(0.00)\end{array}$ & $\begin{array}{c}0.08 \\
(0.00)\end{array}$ \\
\hline Male & $\begin{array}{c}0.38 \\
(0.04)\end{array}$ & $\begin{array}{c}0.42 \\
(0.04)\end{array}$ & $\begin{array}{c}0.50 \\
(0.04)\end{array}$ \\
\hline \multicolumn{4}{|l|}{ Race (ref. White) } \\
\hline Black & & $\begin{array}{c}0.56 \\
(0.04)\end{array}$ & $\begin{array}{c}0.37 \\
(0.04)\end{array}$ \\
\hline Other race + unknown & & $\begin{array}{c}0.18 \\
(0.11)\end{array}$ & $\begin{array}{c}0.13 \\
(0.11)\end{array}$ \\
\hline Log income, centered & & & $\begin{array}{c}-0.13 \\
(0.01)\end{array}$ \\
\hline \multicolumn{4}{|l|}{ Education (ref. < HS) } \\
\hline High school & & & $\begin{array}{c}-0.02 \\
(0.05)\end{array}$ \\
\hline Some college & & & $\begin{array}{c}-0.27 \\
(0.07)\end{array}$ \\
\hline College & & & $\begin{array}{c}-0.64 \\
(0.07)\end{array}$ \\
\hline Constant & $\begin{array}{c}-9.65 \\
(0.08)\end{array}$ & $\begin{array}{c}-9.96 \\
(0.08)\end{array}$ & $\begin{array}{c}-9.68 \\
(0.09)\end{array}$ \\
\hline Slope & $\begin{array}{c}0.13 \\
(0.00)\end{array}$ & $\begin{array}{c}0.13 \\
(0.00)\end{array}$ & $\begin{array}{c}0.13 \\
(0.00)\end{array}$ \\
\hline AIC & 8667 & 8497 & 8239 \\
\hline Deaths & 2719 & 2719 & 2719 \\
\hline Person-years & 621810 & 621810 & 621810 \\
\hline
\end{tabular}


Table 2: Cox Survival Models on the effect of Imprisonment on Mortality, Unweighted, PSID 1968-2013

\begin{tabular}{|c|c|c|c|c|}
\hline & M1 & M1 MSM & M2 & M2 MSM \\
\hline Prison & $\begin{array}{c}0.69 \\
(0.13)\end{array}$ & $\begin{array}{c}0.63 \\
(0.15)\end{array}$ & $\begin{array}{c}0.74 \\
(0.13)\end{array}$ & $\begin{array}{c}0.70 \\
(0.16)\end{array}$ \\
\hline Age & $\begin{array}{c}0.08 \\
(0.00)\end{array}$ & $\begin{array}{c}0.08 \\
(0.00)\end{array}$ & $\begin{array}{c}0.07 \\
(0.00)\end{array}$ & $\begin{array}{c}0.08 \\
(0.00)\end{array}$ \\
\hline Male & $\begin{array}{c}0.49 \\
(0.04)\end{array}$ & $\begin{array}{c}0.44 \\
(0.04)\end{array}$ & $\begin{array}{c}0.50 \\
(0.04)\end{array}$ & $\begin{array}{c}0.43 \\
(0.04)\end{array}$ \\
\hline \multicolumn{5}{|l|}{ Race (.ref. White) } \\
\hline Black & $\begin{array}{c}0.36 \\
(0.04)\end{array}$ & $\begin{array}{c}0.53 \\
(0.04)\end{array}$ & $\begin{array}{c}0.24 \\
(0.04)\end{array}$ & $\begin{array}{c}0.52 \\
(0.04)\end{array}$ \\
\hline Other race + Unknown & $\begin{array}{c}0.07 \\
(0.11)\end{array}$ & $\begin{array}{c}0.18 \\
(0.11)\end{array}$ & $\begin{array}{c}-0.08 \\
(0.11)\end{array}$ & $\begin{array}{c}0.06 \\
(0.12)\end{array}$ \\
\hline Log Income, centered & $\begin{array}{c}-0.14 \\
(0.01)\end{array}$ & & $\begin{array}{c}-0.12 \\
(0.01)\end{array}$ & \\
\hline \multicolumn{5}{|l|}{ Education (ref. $<$ HS) } \\
\hline High school & $\begin{array}{c}-0.03 \\
(0.05)\end{array}$ & & $\begin{array}{c}0.12 \\
(0.05)\end{array}$ & \\
\hline Some college & $\begin{array}{c}-0.27 \\
(0.07)\end{array}$ & & $\begin{array}{c}-0.05 \\
(0.07)\end{array}$ & \\
\hline College & $\begin{array}{c}-0.63 \\
(0.07)\end{array}$ & & $\begin{array}{c}-0.35 \\
(0.07)\end{array}$ & \\
\hline Poor health & & & $\begin{array}{c}1.00 \\
(0.04)\end{array}$ & \\
\hline Deaths & 2719 & 2719 & 2564 & 2564 \\
\hline Person-years & 621810 & 621810 & 595659 & 595659 \\
\hline
\end{tabular}


Table 3: Cox Survival Models on the effect of Imprisonment on Mortality, Weighted, PSID 1968-2013

\begin{tabular}{lcccc}
\hline & M1 & M1 MSM & M2 & M2 MSM \\
\hline Prison & 0.99 & 0.88 & 0.91 & 0.92 \\
Age & $(0.18)$ & $(0.24)$ & $(0.18)$ & $(0.25)$ \\
Male & 0.09 & 0.09 & 0.08 & 0.09 \\
& $(0.00)$ & $(0.00)$ & $(0.00)$ & $(0.00)$ \\
Race (ref. White) & 0.49 & 0.43 & 0.50 & 0.42 \\
& $(0.05)$ & $(0.05)$ & $(0.05)$ & $(0.05)$ \\
Black & & & & \\
Other race + Unknown & 0.34 & 0.47 & 0.23 & 0.49 \\
Log Income, centered & $(0.07)$ & $(0.07)$ & $(0.08)$ & $(0.07)$ \\
& 0.02 & 0.12 & -0.08 & 0.03 \\
Education (ref. $<$ HS) & $(0.14)$ & $(0.13)$ & $(0.13)$ & $(0.15)$ \\
High school & -0.14 & & -0.12 & \\
Some college & $(0.01)$ & & $(0.01)$ & \\
College & & & & \\
Poor health & 0.01 & & 0.14 & \\
& $(0.07)$ & & $-0.06)$ & \\
\hline Deaths & -0.26 & & $(0.09)$ & \\
Person-years & $(0.09)$ & & -0.30 & \\
\hline Robust standard errors in parenthesis. & -0.58 & & $0.10)$ & \\
\hline
\end{tabular}


Table 4: Imprisonment Contribution to Mortality Gap, U.S. and U.K. (England \& Wales)

\begin{tabular}{lccccc}
\hline Age group & $\beta_{\text {prison }}$ & Hazard Ratio & $P_{(x)}$ & $A_{(x)}$ & $B_{(x)}$ \\
\hline $20-45$ & 0.55 & 1.73 & 0.02 & 0.97 & 0.03 \\
$20-45$ & 0.63 & 1.88 & 0.02 & 0.97 & 0.03 \\
$20-45$ & 0.69 & 1.99 & 0.02 & 0.97 & 0.03 \\
$20-45$ & 0.74 & 2.10 & 0.02 & 0.96 & 0.04 \\
$20-45$ & 0.82 & 2.27 & 0.02 & 0.96 & 0.04 \\
$20-45$ & 0.88 & 2.41 & 0.02 & 0.95 & 0.05 \\
$20-45$ & 0.99 & 2.69 & 0.02 & 0.94 & 0.06 \\
& & & & & \\
$20-70$ & 0.55 & 1.73 & 0.02 & 0.96 & 0.04 \\
$20-70$ & 0.63 & 1.88 & 0.02 & 0.95 & 0.05 \\
$20-70$ & 0.69 & 1.99 & 0.02 & 0.94 & 0.06 \\
$20-70$ & 0.74 & 2.10 & 0.02 & 0.94 & 0.06 \\
$20-70$ & 0.82 & 2.27 & 0.02 & 0.93 & 0.07 \\
$20-70$ & 0.88 & 2.41 & 0.02 & 0.92 & 0.08 \\
$20-70$ & 0.99 & 2.69 & 0.02 & 0.90 & 0.10 \\
\hline
\end{tabular}

Note: $J_{(x)}=707, j_{(x)}=148, M U_{(20-45)}=4.35, m u_{(20-45)}=2.69, M U_{(20-70)}$ $=35.6 ; m u_{(20-70)}=27.7$. Incarceration rates per 100,000; Mortality rates per 1,000 . 


\section{Figures}

Figure 1: Individual Pathways between Incarceration and Mortality

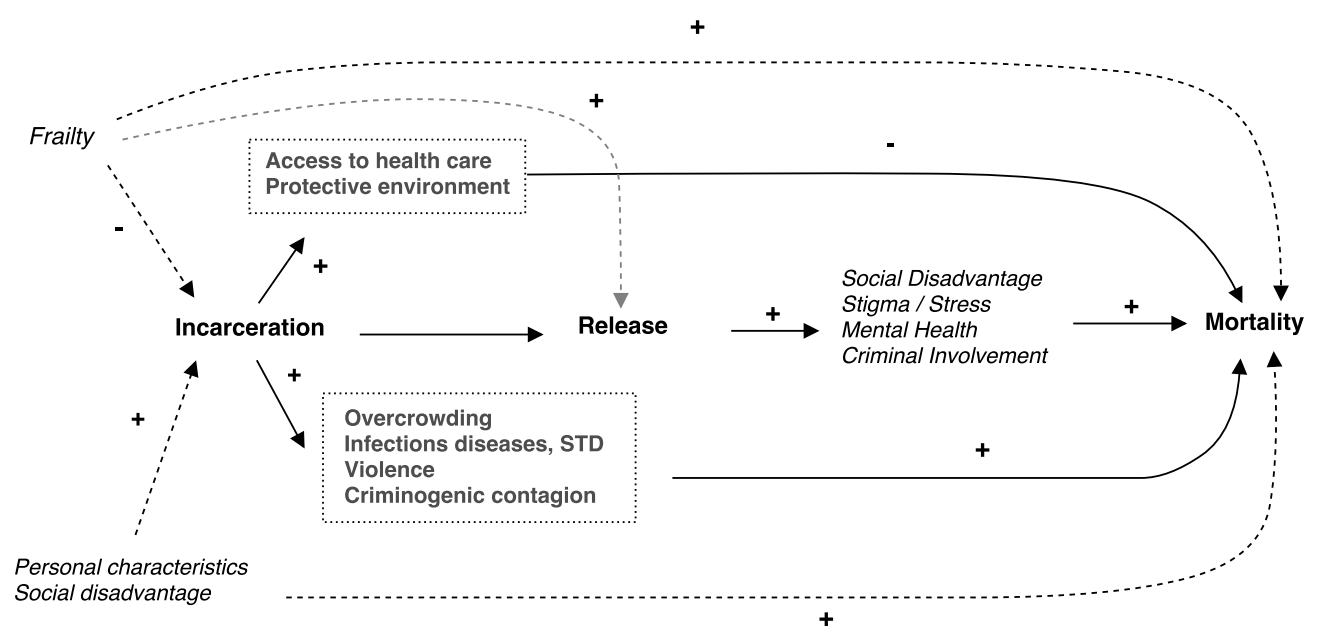


Figure 2: Proportion Respondents in Prison, PSID 1968-2013

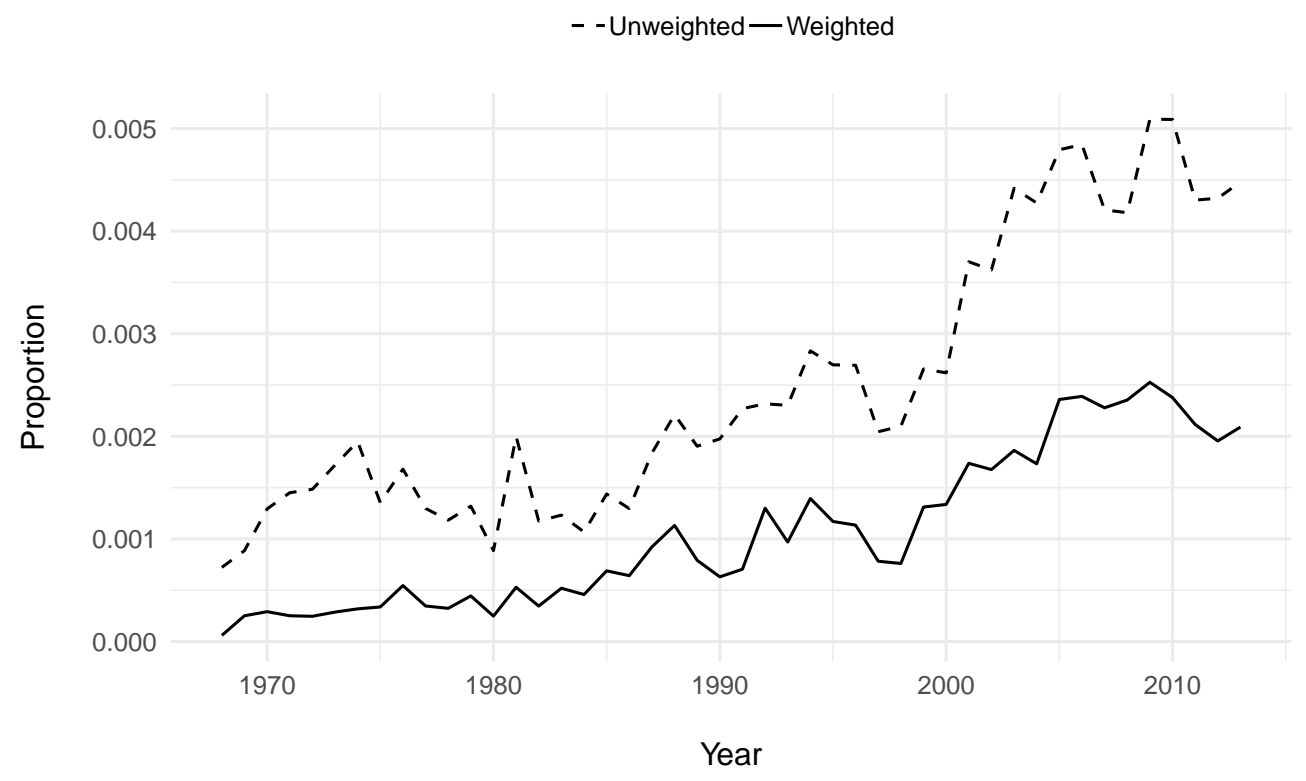


Figure 3: Cumulative Incidence Mortality (M1, Table 2)

(a) At age 18

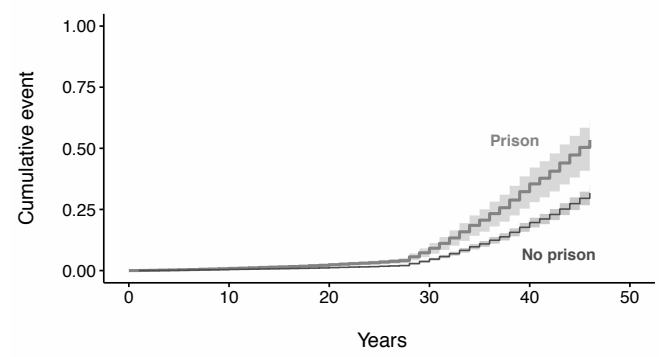

(b) At age 30

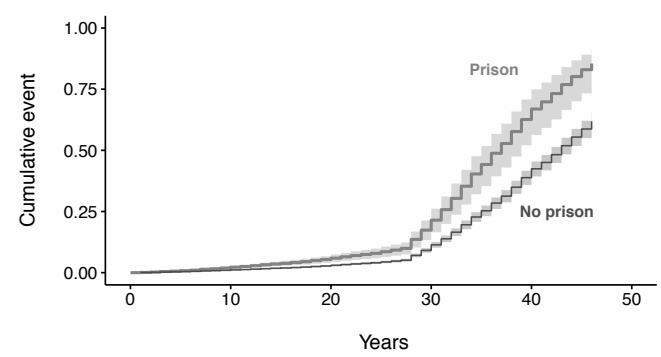

Note: Predicted probabilities for male, black, less than high school, and average income. 


\section{Online Appendix}

The code to reproduce the analysis of The Consequences of Incarceration for Mortality in the United States is available in https://github.com/sdaza/mortality-incarceration-paper. Some of the data we use are restricted, and was obtained under special contractual arrangements to protect the anonymity of respondents. These data are not available from the authors. Those interested in obtaining PSID restricted data should contact PSIDHelp@ isr.umich.edu.

\section{Incarceration Measures}

The incarceration indicators available in the PSID include non-response information on whether a member of a household was incarcerated at the time of the interview, and a set of questions on involvement with the criminal justice system. One of those questions asked in 1995 if respondents have been in jail or prison. Unfortunately, we cannot distinguish between prison and jail in our data. We acknowledge that prison and jail are different spaces in terms of the resources and treatment of inmates, which might have an impact on their health and mortality. However, given the limitations of our data, we use incarceration and imprisonment interchangeable.

In the case of the non-response incarceration, if a respondent in the PSID was not the only member of their family unit (FU), his incarceration status usually came from other family unit members (e.g., wife, kids). Incarcerated respondents did not get interviewed. However, they are flagged as institutionalized and followed in the next wave. Their family may still be interviewed, provided she had a family unit larger than one in the previous wave. Thus, if a respondent is the only FU member and goes to jail, there will not be an interview at all, but his extended family would be usually contacted to learn his status. If that person lives with his spouse and children, and he goes to jail, there will be an interview in which his spouse will likely be the respondent and the incarcerated respondent will be coded as in an institution for that wave. In the case of the incarceration indicator in 1995, an imprisonment question was asked only to respondents who were 13-49 years old and attended school sometime. 
Although both indicators provide useful information on respondents' incarceration experiences, they have some shortcomings. In the case of non-response incarceration, we only have information when the household to which the respondent belongs was interviewed. We do not know what happened before respondents started participating in the study. Similarly, we do not know their incarceration status during periods when individuals were not interviewed. The 1995 incarceration variable, in contrast, is retrospective, providing information from respondents' criminal justice contacts before 1996. However, that question was posed to panel members who survived until 1995 and could contaminate estimates with survivor biases. We finally combined both sources of information and adjust for survival bias.

A general concern when studying incarceration effects using survey data is that a substantial segment of the US population has been rendered invisible in many official statistics, specially incarcerated people who are very often omitted from sampling frames (Pettit, 2012). We are well aware of the potential problems posed by of missing individuals of interest for the question we pose at the outset. However, although PSID does not consider incarcerated people in the first wave, it does takes into account both retrospective and prospective incarceration events. Surely, this is not an ideal set up but, provided there are enough young respondents who are followed over time (the PSID follows new family members and the NLSY79 includes a very young sample, 12-16 year-old respondents), the estimates we obtain should be close to those we would have obtained had the first wave included those incarcerated at the time.

Figure $\mathrm{S} 1$ show the PSID distributions of the age of death, first imprisonment using the data available, and the difference between the age of death and first imprisonment.

\section{Simulation Check}

To check our data setup, we implement a simple multi-state model simulation with three transition rates (incarceration, dying without experiencing incarceration, and dying after incarceration) and three states (being born, being in prison, and dying, see Figure S2). 
We use age-specific mortality rates from the US life-table, the US age population distribution, and a constant imprisonment rate of 0.007 for ages $18-45$, otherwise the incarceration rate is set to 0. In our model, being in prison increases age-specific mortality rates by 1.90 . Individuals enter to the observation window at different ages as in the PSID, and right censoring is defined using a uniform distribution, censoring $=$ uniform $\left(a_{g} e_{e n t e r}, 120\right)$. Then, we generate 1000 samples using 10,000 individuals. The average start age across simulations is 37.1 .

Finally, we run 1,000 Cox models adjusting by a time-varying prison variable (coded as 1 after the incarceration transition occurs) and age (non-variant covariate). The estimated mean of mortality hazard ratios from 1,000 simulations is 1.879 , pretty close to 1.90 , so we conclude that our data setup is correct. The simulation results are available at https://github.com/sdaza/mortalityincarceration-paper/blob/master/simulation/simulation.ipynb.

\section{Model Specifications}

\subsection{Time-varying covariates and attrition}

By using Marginal Structural Models (MSM), we address two problematic situations pointed out by Hernán and Robins, 2006 when employing time-varying covariates: (1) There exists a timedependent covariate that is both a risk factor for mortality and also predicts subsequent exposure (e.g., income); (2) Past exposure history (incarceration) might predicts risk factors (e.g., income or health). For instance, past income is a time-dependent confounder for the effect of incarceration on survival, because it is a risk factor for mortality and a predictor of the onset of incarceration. Addi-

tionally, prior incarceration is an independent predictor of subsequent income. Standard methods (i.e., Cox regression) that estimate mortality rates at a given time (age) using a summary measure of income or health up to that time (age) may produce biased estimates of the association of incarceration whether or not one adjusts for past income in the analysis.

Following van der Wal and Geskus, 2011, we compute stabilized inverse probability weights to correct the biases related to time-varying covariates. We also adjust these weights using the 
association between incarceration and attrition as a way to confront informative censoring. The specification of our models are available in our online repository. The marginal structural models adjust both for the incarceration indicator and baseline covariates (i.e., time-invariant covariates) as we include them in the numerator to stabilize weights.

\subsection{Goodness of fit}

We explore different specifications and examine goodness of fit. We test the proportional hazard assumption of Cox models using Schoenfeld residuals (i.e., observed minus expected values of the covariates at each failure time). When we find indications of departures from proportionality, we introduce an interaction term between the covariate and the log of time. In general, that interactions are noisy and do not change the average results of the effect of imprisonment. Thus, we decide to present the simplest models in the paper.

We also estimate models adjusting for unmeasured frailty by introducing a random proportionality factor that modifies the hazard function of a respondent (Mills, 2011; Broström, 2012). Specifically, we estimate a shared frailty model with a gamma distribution fit (with a mean of 1 and variance $\theta$ ) based on the long-term family identifier available and individual identifier in the PSID. We do not observe substantial differences in the estimates.

\subsection{Sampling Weights}

We estimate models with and without sampling weights. Our analytic sample includes respondents who are not PSID sample members, according to the PSID terminology. Those respondents have an unknown probability of selection. We assign sample weights to non-sample respondents using the following procedure: After defining our analytic sample, we consider only the first longitudinal sample weight available for individual $i$ at time $t_{0}$ (i.e., the sample weight at the start of the period of observation for individual $i$ ). If the individual $i$ did not have a sample weight, we pooled the weights from the members of his family unit $u$ at time $t_{0}$, and compute the average. We estimate models without and with sample to assess how sensitive they are to this procedure. 


\subsection{Missing data}

We implement two strategies to deal with missing data. First, we impute time-varying covariates (e.g., education, income, health) using the Last Observation Carried Forward (LSCF) procedure. This strategy is not problematic regarding stable and monotonic variables such education, but can be questionable with respect to variables such health and income where more change over time is expected. When health is poor, we should not expect much change, specially if the time between missing periods is short. Income, on the other hand, will change due to aging and structural economic factors. In addition to LSCF, we also impute backwards only when the first incarceration episode (according to the PSID) occurred after the first record of the covariate of interest. We remove respondents that do not comply with this rule. For the rest of time-invariable variables, we exclude observations with missing data and without sampling weights. Regarding our key independent variable (incarceration), we impute unobserved periods with zeros (i.e., no event). If imprisonment indeed increases mortality, our incarceration variable and imputation procedure would underestimate the association, particularly if it is unlikely that ex-inmates have lower risk of dying after their release.

Our second strategy is multiple imputation. We implement multilevel models to impute missing values using both time-invariant and time-variant covariates. For example, to impute income we specify a model such as:

$$
\begin{aligned}
\text { income }_{j}= & \alpha+\text { year }_{i}+\text { male }_{i}+\text { race }_{i}+\text { age }_{i}+ \\
& \text { edu }_{j}+\text { prison }_{j}+\text { prison }_{95_{j}}+\text { health }_{j}+\text { dropout }_{j}+\text { died }_{j}+ \\
& \delta_{i}+\varepsilon_{j}
\end{aligned}
$$

Where $j$ represents each observation in a long-format dataset, and $i$ individuals. $\delta_{i}$ represents the random effect at the individual level. We examine the distribution of the imputed variables by age and year to check they were reasonable. Then, we pool estimates from 100 imputations. Results are displayed in Tables $\mathbf{S 1}$ and $\mathbf{S} 2$. 


\subsection{NLSY 79}

To validate our data setup and extent the analysis by Massoglia, Pare, Schnittker, and Gagnon, 2014 using NLSY79, we estimate the association between imprisonment and mortality using the complete NLSY sample (584 deaths in total) and implement marginal structural models (MSM) to adjust by time-varying confounders.

We estimate Cox-models using sampling weights and adjusting for age (set of dummies), gender, race, income, education, work status, marriage, poor health, delinquency at the baseline, and parent's education. The number of respondents who here incarcerated and died during the observation period of the NLSY was 81 , and 17 of them were women. The average number of years between the last spell and the year of death was 8.4 (median =7), about $40 \%$ lower than the PSID. As expected, deaths occurred on average at younger ages $(41$, median $=43)$, and $42 \%$ of them occurred within the first 5 years after release at an average age of 37. This is different from the PSID, where a much smaller proportion of deaths (22\%) occurred within the first 5 years.

Tables S3 and S4 display Cox models using both unweighted and weighted NLSY samples and four model specifications: adjusting or not by poor health and estimation or not of MSMs. Unweighted imprisonment coefficients are close to zero with large uncertainty bounds for the size of the effects. Weighted point estimates, on the other hand, are negative and also uncertain. The other covariates are properly signed: males have a higher risk of mortality; income, education, working status, and married are associated with lower risks; and, finally, poor (self-reported) health is a strong predictor of mortality. Our marginal structural models, in contrast, show positive and more consistent coefficients for imprisonment, with hazard ratios ranging from 1.73 to 1.77 . In summary, we are able to reproduce key results from PSID when using marginal structural models and dealing with time-covariate adjustments (Hernán \& Robins, 2006). 


\section{References}

Broström, G. (2012). Event history analysis with R. CRC Press.

Hernán, M. A. \& Robins, J. M. (2006). Estimating causal effects from epidemiological data. Journal of Epidemiology and Community Health (1979-), 60(7), 578-586.

Massoglia, M., Pare, P.-P., Schnittker, J., \& Gagnon, A. (2014). The relationship between incarceration and premature adult mortality: Gender specific evidence. Social Science Research, 46, $142-154$.

Mills, M. (2011). Introducing survival and event history analysis. Sage Publications.

Pettit, B. (2012). Invisible Men: Mass Incarceration and the Myth of Black Progress (First Edition). New York: Russell Sage Foundation.

van der Wal, W. M. \& Geskus, R. B. (2011). Ipw: An R package for inverse probability weighting. Journal of Statistical Software, 43(13), 1-23. 


\section{Figures and Tables}

Figure S1: PSID Distribution Age of Death an Imprisonment

(a) Distribution Age of Death

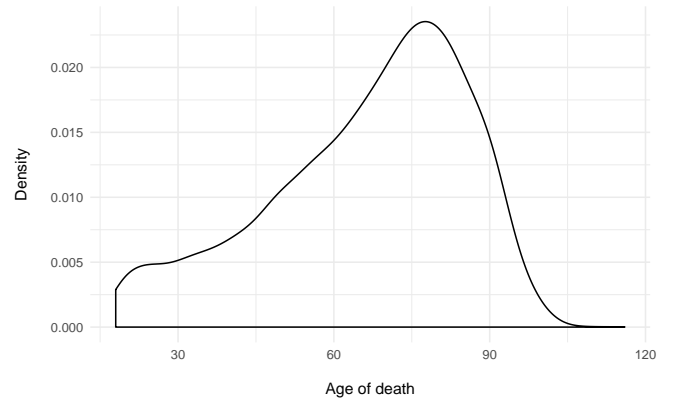

(b) Distribution Age First Imprisonment

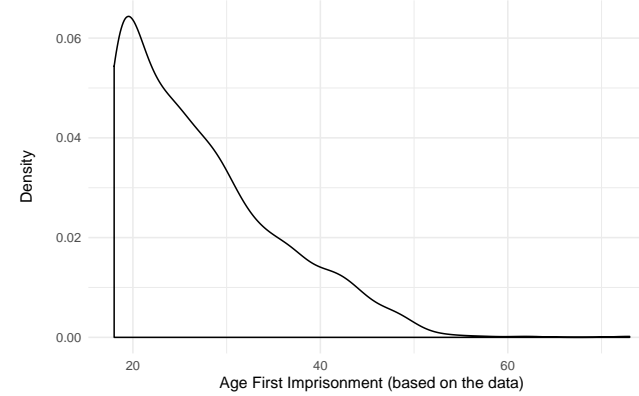

(c) Difference Age of Death and Imprisonment

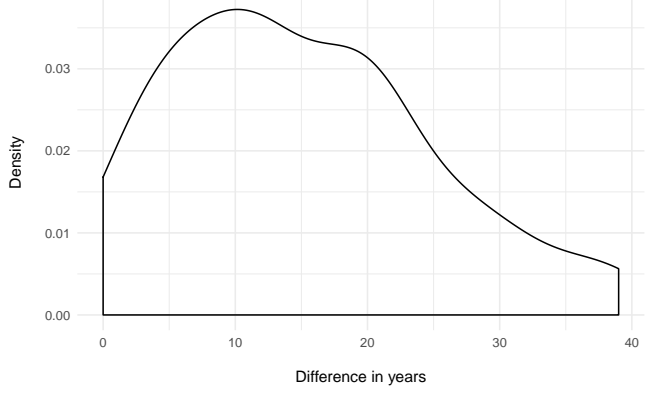


Figure S2: Simulated State Transitions

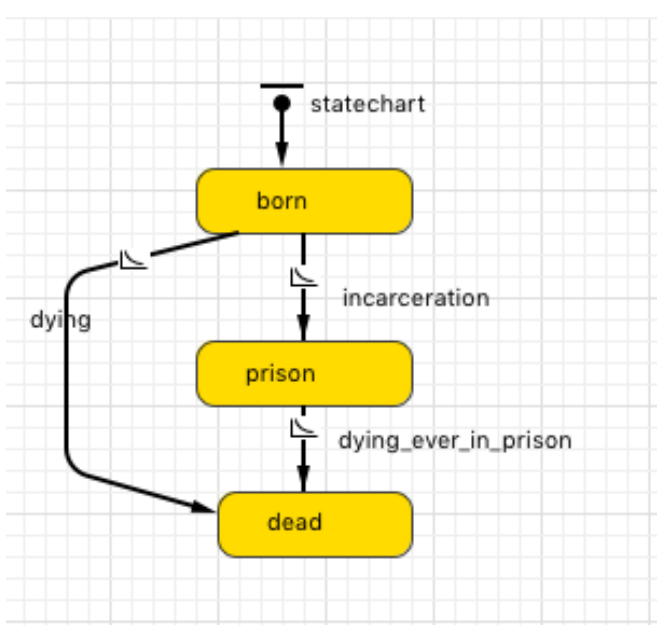


Table S1: Cox Survival Models on the effect of Imprisonment on Mortality, 100 Imputations, Unweighted, PSID 1968-2013

\begin{tabular}{|c|c|c|c|c|}
\hline & M1 & M1 MSM & M2 & M2 MSM \\
\hline Prison & $\begin{array}{c}0.71 \\
(0.16)\end{array}$ & $\begin{array}{c}0.63 \\
(0.26)\end{array}$ & $\begin{array}{c}0.71 \\
(0.15)\end{array}$ & $\begin{array}{c}0.62 \\
(0.26)\end{array}$ \\
\hline Age & $\begin{array}{c}0.08 \\
(0.00)\end{array}$ & $\begin{array}{c}0.08 \\
(0.00)\end{array}$ & $\begin{array}{c}0.07 \\
(0.00)\end{array}$ & $\begin{array}{c}0.08 \\
(0.00)\end{array}$ \\
\hline Male & $\begin{array}{c}0.44 \\
(0.04)\end{array}$ & $\begin{array}{c}0.42 \\
(0.04)\end{array}$ & $\begin{array}{c}0.45 \\
(0.04)\end{array}$ & $\begin{array}{c}0.42 \\
(0.04)\end{array}$ \\
\hline \multicolumn{5}{|l|}{ Race (ref. White) } \\
\hline Black & $\begin{array}{c}0.37 \\
(0.05)\end{array}$ & $\begin{array}{c}0.48 \\
(0.05)\end{array}$ & $\begin{array}{c}0.33 \\
(0.05)\end{array}$ & $\begin{array}{c}0.48 \\
(0.05)\end{array}$ \\
\hline Other race + Unknown & $\begin{array}{c}0.06 \\
(0.10)\end{array}$ & $\begin{array}{c}0.14 \\
(0.11)\end{array}$ & $\begin{array}{c}0.03 \\
(0.10)\end{array}$ & $\begin{array}{c}0.14 \\
(0.11)\end{array}$ \\
\hline Log Income, centered & $\begin{array}{c}-0.04 \\
(0.02)\end{array}$ & & $\begin{array}{c}-0.02 \\
(0.02)\end{array}$ & \\
\hline \multicolumn{5}{|l|}{ Education (ref. < HS) } \\
\hline High school & $\begin{array}{c}-0.08 \\
(0.05)\end{array}$ & & $\begin{array}{c}-0.03 \\
(0.05)\end{array}$ & \\
\hline Some college & $\begin{array}{c}-0.34 \\
(0.07)\end{array}$ & & $\begin{array}{c}-0.26 \\
(0.07)\end{array}$ & \\
\hline College & $\begin{array}{c}-0.73 \\
(0.07)\end{array}$ & & $\begin{array}{c}-0.63 \\
(0.07)\end{array}$ & \\
\hline Poor health & & & $\begin{array}{c}0.53 \\
(0.07)\end{array}$ & \\
\hline Person-years & 633519 & 633519 & 633519 & 633519 \\
\hline Deaths & 2803 & 2803 & 2803 & 2803 \\
\hline
\end{tabular}


Table S2: Cox Survival Models on the effect of Imprisonment on Mortality, 100 Imputations, Weighted, PSID 1968-2013

\begin{tabular}{|c|c|c|c|c|}
\hline & M1 & M1 MSM & M2 & M2 MSM \\
\hline Prison & $\begin{array}{c}0.86 \\
(0.26)\end{array}$ & $\begin{array}{c}0.82 \\
(0.41)\end{array}$ & $\begin{array}{c}0.85 \\
(0.23)\end{array}$ & $\begin{array}{c}0.82 \\
(0.41)\end{array}$ \\
\hline Age & $\begin{array}{c}0.09 \\
(0.00)\end{array}$ & $\begin{array}{c}0.09 \\
(0.00)\end{array}$ & $\begin{array}{c}0.08 \\
(0.00)\end{array}$ & $\begin{array}{c}0.09 \\
(0.00)\end{array}$ \\
\hline Male & $\begin{array}{c}0.46 \\
(0.05)\end{array}$ & $\begin{array}{c}0.42 \\
(0.05)\end{array}$ & $\begin{array}{c}0.46 \\
(0.05)\end{array}$ & $\begin{array}{c}0.42 \\
(0.05)\end{array}$ \\
\hline \multicolumn{5}{|l|}{ Race (ref. White) } \\
\hline Black & $\begin{array}{c}0.31 \\
(0.10)\end{array}$ & $\begin{array}{c}0.40 \\
(0.11)\end{array}$ & $\begin{array}{c}0.26 \\
(0.10)\end{array}$ & $\begin{array}{c}0.40 \\
(0.11)\end{array}$ \\
\hline Other race + Unknown & $\begin{array}{c}-0.05 \\
(0.13)\end{array}$ & $\begin{array}{c}0.03 \\
(0.13)\end{array}$ & $\begin{array}{c}-0.07 \\
(0.12)\end{array}$ & $\begin{array}{c}0.03 \\
(0.13)\end{array}$ \\
\hline Log Income, centered & $\begin{array}{c}-0.05 \\
(0.02)\end{array}$ & & $\begin{array}{c}-0.03 \\
(0.02)\end{array}$ & \\
\hline \multicolumn{5}{|l|}{ Education (ref. $<$ HS) } \\
\hline High school & $\begin{array}{c}-0.04 \\
(0.07)\end{array}$ & & $\begin{array}{c}0.01 \\
(0.07)\end{array}$ & \\
\hline Some college & $\begin{array}{c}-0.31 \\
(0.09)\end{array}$ & & $\begin{array}{r}-0.20 \\
(0.09)\end{array}$ & \\
\hline College & $\begin{array}{c}-0.68 \\
(0.09)\end{array}$ & & $\begin{array}{c}-0.55 \\
(0.10)\end{array}$ & \\
\hline Poor health & & & $\begin{array}{c}0.74 \\
(0.07)\end{array}$ & \\
\hline Person-years & 633519 & 633519 & 633519 & 633519 \\
\hline Deaths & 2803 & 2803 & 2803 & 2803 \\
\hline
\end{tabular}


Table S3: Cox Survival Models on the effect of Imprisonment on Mortality, Unweighted, NLSY79 1980-2014

\begin{tabular}{|c|c|c|c|c|}
\hline & M1 & M1 MSM & M2 & M2 MSM \\
\hline Prison & $\begin{array}{c}0.00 \\
(0.16)\end{array}$ & $\begin{array}{c}0.57 \\
(0.17)\end{array}$ & $\begin{array}{c}0.03 \\
(0.16)\end{array}$ & $\begin{array}{c}0.57 \\
(0.17)\end{array}$ \\
\hline Male & $\begin{array}{c}0.54 \\
(0.09)\end{array}$ & $\begin{array}{c}0.50 \\
(0.09)\end{array}$ & $\begin{array}{c}0.54 \\
(0.09)\end{array}$ & $\begin{array}{c}0.50 \\
(0.09)\end{array}$ \\
\hline \multicolumn{5}{|c|}{ Race (ref. Non-Hispanics/Blacks) } \\
\hline Black & $\begin{array}{c}0.01 \\
(0.10)\end{array}$ & $\begin{array}{c}0.43 \\
(0.10)\end{array}$ & $\begin{array}{c}0.03 \\
(0.10)\end{array}$ & $\begin{array}{c}0.44 \\
(0.10)\end{array}$ \\
\hline Hispanic & $\begin{array}{c}-0.22 \\
(0.13)\end{array}$ & $\begin{array}{c}0.01 \\
(0.12)\end{array}$ & $\begin{array}{c}-0.19 \\
(0.13)\end{array}$ & $\begin{array}{c}0.01 \\
(0.12)\end{array}$ \\
\hline Log Income, centered & $\begin{array}{c}-0.02 \\
(0.02)\end{array}$ & & $\begin{array}{c}-0.03 \\
(0.02)\end{array}$ & \\
\hline \multicolumn{5}{|l|}{ Education (ref. < HS) } \\
\hline High school & $\begin{array}{c}-0.16 \\
(0.11)\end{array}$ & & $\begin{array}{c}-0.15 \\
(0.11)\end{array}$ & \\
\hline Some college & $\begin{array}{r}-0.38 \\
(0.15)\end{array}$ & & $\begin{array}{c}-0.35 \\
(0.15)\end{array}$ & \\
\hline College & $\begin{array}{c}-0.43 \\
(0.18)\end{array}$ & & $\begin{array}{c}-0.37 \\
(0.18)\end{array}$ & \\
\hline Working & $\begin{array}{r}-1.06 \\
(0.10)\end{array}$ & & $\begin{array}{c}-0.74 \\
(0.11)\end{array}$ & \\
\hline Married & $\begin{array}{r}-0.87 \\
(0.10)\end{array}$ & & $\begin{array}{c}-0.81 \\
(0.10)\end{array}$ & \\
\hline Poor health & & & $\begin{array}{c}0.90 \\
(0.11)\end{array}$ & \\
\hline Deaths & 584 & 584 & 584 & 584 \\
\hline Person-years & 297282 & 297282 & 297282 & 297282 \\
\hline
\end{tabular}


Table S4: Cox Survival Models on the effect of Imprisonment on Mortality, Weighted, NLSY79 1980-2014

\begin{tabular}{|c|c|c|c|c|}
\hline & M1 & M1 MSM & M2 & M2 MSM \\
\hline Prison & $\begin{array}{c}-0.27 \\
(0.20)\end{array}$ & $\begin{array}{c}0.55 \\
(0.19)\end{array}$ & $\begin{array}{c}-0.25 \\
(0.20)\end{array}$ & $\begin{array}{c}0.55 \\
(0.19)\end{array}$ \\
\hline Male & $\begin{array}{c}0.54 \\
(0.11)\end{array}$ & $\begin{array}{c}0.49 \\
(0.11)\end{array}$ & $\begin{array}{c}0.55 \\
(0.11)\end{array}$ & $\begin{array}{c}0.49 \\
(0.11)\end{array}$ \\
\hline \multicolumn{5}{|c|}{ Race (ref. Non-Hispanics/Blacks) } \\
\hline Black & $\begin{array}{c}-0.12 \\
(0.10)\end{array}$ & $\begin{array}{c}0.40 \\
(0.09)\end{array}$ & $\begin{array}{c}-0.09 \\
(0.10)\end{array}$ & $\begin{array}{c}0.40 \\
(0.09)\end{array}$ \\
\hline Hispanic & $\begin{array}{c}-0.34 \\
(0.13)\end{array}$ & $\begin{array}{c}-0.05 \\
(0.13)\end{array}$ & $\begin{array}{c}-0.29 \\
(0.13)\end{array}$ & $\begin{array}{r}-0.04 \\
(0.13)\end{array}$ \\
\hline Log Income, centered & $\begin{array}{c}-0.02 \\
(0.02)\end{array}$ & & $\begin{array}{c}-0.02 \\
(0.02)\end{array}$ & \\
\hline \multicolumn{5}{|l|}{ Education (ref. < HS) } \\
\hline High school & $\begin{array}{c}-0.04 \\
(0.14)\end{array}$ & & $\begin{array}{c}-0.04 \\
(0.14)\end{array}$ & \\
\hline Some college & $\begin{array}{c}-0.22 \\
(0.18)\end{array}$ & & $\begin{array}{c}-0.19 \\
(0.18)\end{array}$ & \\
\hline College & $\begin{array}{c}-0.36 \\
(0.21)\end{array}$ & & $\begin{array}{c}-0.29 \\
(0.21)\end{array}$ & \\
\hline Working & $\begin{array}{c}-1.14 \\
(0.14)\end{array}$ & & $\begin{array}{c}-0.76 \\
(0.14)\end{array}$ & \\
\hline Married & $\begin{array}{r}-1.07 \\
(0.14)\end{array}$ & & $\begin{array}{c}-1.00 \\
(0.14)\end{array}$ & \\
\hline Poor health & & & $\begin{array}{c}0.97 \\
(0.14)\end{array}$ & \\
\hline Deaths & 584 & 584 & 584 & 584 \\
\hline Person-years & 297282 & 297282 & 297282 & 297282 \\
\hline
\end{tabular}

